\title{
Adsorption of Nicotine on Calcinated and Modified Compressed Coffee Residue CACS and Its Surface Properties
}

\author{
Y. Walid Al-Bizreh ${ }^{1}$, Rasha Al-mostafa ${ }^{1 *}$, Malak AL-Joubbeh ${ }^{1,2}$ \\ ${ }^{1}$ Department of Chemistry, Faculty of Sciences, Damascus University, Syria. \\ ${ }^{2}$ Syrian Private University, Damascus, Syria.
}

\begin{abstract}
DRIED compressed coffee residue was calcinated at a temperature of $400{ }^{\circ} \mathrm{C}$ for 4 hours. A It was analyzed quantitatively and qualitatively by using X-Ray Fluorescence (XRF) spectroscopy. The coffee carbon surface was modified with oleum. The surface properties of the sample were studied by using the FTIR spectroscopy after each treatment resulting new different peaks that indicate the modification with oleum. Besides, other peaks that indicate the adsorption of nicotine on its surface were obvious. The concentrations of nicotine in the studied solutions were measured by using the spectrophotometry, the nicotine adsorption on the studied adsorbent followed the pseudo second-order model. The effect of nicotine concentration was also studied at the temperatures of $20-30-35-40{ }^{\circ} \mathrm{C}$; an increase of the nicotine adsorption was noticed with the increase of the initial concentration at each of the studied temperatures; the adsorption curves fitted the Langmuir and Freundlich isotherms models. In addition, the thermodynamic parameters of the surface adsorption interaction $\Delta \mathrm{G}^{0}, \Delta \mathrm{H}^{0}, \Delta \mathrm{S}^{0}$ were determined, the resulting values showed that the interaction is endothermic and the adsorption is of chemical nature. Besides, a mechanism for the adsorption of nicotine on modified compressed coffee residue carbon (CACS) was suggested presuming the participation of the two nitrogen atoms in the polar nicotine molecule.
\end{abstract}

Keywords: Adsorption, Nicotine, Oleum, Coffee residue.

\section{Introduction}

Nicotine is considered to be one of the alkaloids and it's a highly toxic substance whereas its fatal dose reaches to $40-60 \mathrm{mg} / \mathrm{kg}$. Besides, nicotine is more toxic than many other alkaloids such as cocaine which has a fatal dose of $1000 \mathrm{mg} / \mathrm{kg}$ [1], Nicotine is an organic compound -3 ( -1 methyl -2 - pyrrolidinyl) pyridine [2], because nicotine is soluble in water, it causes environmental pollution where large amounts of nicotine moves to the wastewater that produced by tobacco's treatment operation and its industrial products, that's how it moves to the groundwater and contaminates it [3], therefore, these wastes, which constitutes a serious threat to the environment and human health, have been classified to be toxic and hazardous substances according to the instructions of the European Union [4], On the other hand, nicotine has recently manifested some benefits to treat certain nerve diseases despite some concerns about it.

This issue has imposed the need not only to separate nicotine and extract it but also to retrieve and purify it [5].

Since most of the water purifications techniques are expensive, the activated carbon is used in the technique of adsorption which is better than other methods for its simplicity and cleanliness to separate the nicotine [6].

Carbon was increasingly used as an adsorbent material for removing organic and inorganic contaminants and that's how there was a huge benefit of the agricultural wastes. In addition, some natural wastes especially the tea leaves and the coffee remains were used as adsorbent materials to remove the traces of the metals that existed in water, such as: treating wastewater containing traces of the metals (Lead, Mercury, Zinc, Copper, Nickel and Cadmium). It's been found that the adsorption of the metal ions falls within isotherm Langmuir equation [7].

A study has been made about the adsorption of lead on the untreated powdered coffee that was produced by the wastes of coffeehouses where

*Corresponding author e-mail: r.mostafachem@yahoo.com.

DOI:10.21608/ejchem.2018.3471.1295

C2017 National Information and Documentation Center (NIDOC) 
the adsorption capacity of lead in the aqueous solutions was $75.95 \mathrm{mg} . \mathrm{g}^{-1}$ [8].

The goal of the work

Preparing an adsorbent material of the activated carbon produced from a modification of the surface of Compressed coffee carbon with oleum for:

- Using the adsorbent material (CACS) for nicotine adsorption from its aqueous solutions

- Using domestic waste to get rid of the environmental contaminants

\section{Materials}

Compressed coffee residue, local waste

Nicotine $\quad \mathrm{C}_{10} \mathrm{H}_{14} \mathrm{~N}_{2}, \quad \mathrm{M}_{\mathrm{w}}=\quad 162.24$ g/mol, purity $>99 \%$, Merck. Sulfuric acid $\mathrm{H}_{2} \mathrm{SO}_{4}, \quad 98 \%$, SDFCL Oleum $\mathrm{H}_{2} \mathrm{SO}_{4} . \mathrm{SO}_{3}$, Homs Refinery. Barium chloride $\mathrm{BaCl}_{2} \cdot 2 \mathrm{H}_{2} \mathrm{O}, \mathrm{M}_{\mathrm{w}}=244.27 \mathrm{~g} /$ mol, purity $99 \%$.

The sample preparation

The compressed coffee residue was dried at the temperature of $105{ }^{\circ} \mathrm{C}$, then it was simply calcinated at $400{ }^{\circ} \mathrm{C}$ for four hours and it was smoothly smashed, the prepared sample (CAC) were analyzed quantitatively and qualitatively by using the X-ray device XRF, the results of the analysis are shown in Table 1.

Table 1 shows that the sample contains a large amount of potassium, alkaline earth metals $(\mathrm{Ca}$, $\mathrm{Sr}$ ), and some transition metals ( $\mathrm{Mn}, \mathrm{Fe}, \mathrm{Ni}, \mathrm{Cu}$ ).

\section{Determination of the nature of surface $(C A C)$}

The coffee carbon surface (CAC) were modified with oleum due to the presence of alkaline sites on its surface, that impede nicotine adsorption, it was shown by soaking $0.5 \mathrm{~g}$ of the (CAC) in $10 \mathrm{ml}$ of acetic acid $(0.05 \mathrm{M})$ for three days. The concentration of acetic acid was reduced after being soaked with the sample. The number of active alkaline sites on the surface of (CAC) was calculated to be $\left(3.20 \times 10^{20}\right)$ alkaline site/g by means of the difference between acid concentrations before and after soaking with the residual of (CAC).

\section{Modification of (CAC)}

The surface of sample was modified with oleum; a weight of it was put in a flask, oleum was dropped slowly with a ratio of $1: 1$, then the mixture was connected to washing bottles. It was isolated for 24 hours, after that, the mixture was put on a filter paper and it was washed with distilled water to make sure that the entire sulfates were removed from the filtrate and it was dried after weighing it at a temperature of $105^{\circ} \mathrm{C}$ until it reached a stable weight, thereby, the new prepared adsorbent has been called (CACS).

Determination of the nature of surface (CACS)

$1 \mathrm{~g}$ of the modified coffee carbon (CACS) was soaked in $10 \mathrm{ml}$ of Sodium Chloride $(3 \mathrm{~N})$ for three days, after soaking, the adsorbent produced hydrogen ions $\left(\mathrm{H}^{+}\right)$, which were titrated with sodium hydroxide $(0.01 \mathrm{~N})$, the number of active acid sites on the surface of (CACS) was determined to be $\left(9.23 \times 10^{20}\right)$ acid site/g.

Nicotine determination by spectrophotometry

A standardized series of nicotine solutions was prepared at different concentrations and diluted with sulfuric acid $(0.05 \mathrm{~N})$. Each solution in

TABLE 1. Results of the quantitatively and qualitatively analysis for the compressed coffee carbon (CAC).

\begin{tabular}{cc}
\hline ppm (concentration) & Element \\
\hline $14670 \pm 1730$ & $\mathrm{~K}$ \\
$4370 \pm 53$ & $\mathrm{Ca}$ \\
$113 \pm 15$ & $\mathrm{Mn}$ \\
$150 \pm 30$ & $\mathrm{Fe}$ \\
$5.2>$ & $\mathrm{Ni}$ \\
$44.4 \pm 4.7$ & $\mathrm{Cu}$ \\
$30.7 \pm 3.8$ & $\mathrm{Zn}$ \\
$<1.85$ & $\mathrm{Br}$ \\
$17.8-2.3$ & $\mathrm{Rb}$ \\
$10.2-1.3$ & $\mathrm{Sr}$ \\
\hline
\end{tabular}


quartz cuvette was measured against blank sample containing sulfuric acid solution [9]. The spectral scanning was made in the range (200-400 nm) of UV to determine the maximum wave length for measuring the absorbance of the solutions of the standardized series, As Fig. 1 shows, $\lambda_{\max }=258$ nm.

Then the absorbance of the standardized series solutions was measured at the maximum wave length that experimentally determined, Fig.2 shows the linearity of the standardized curve was $\mathrm{R}^{2}=0.999$ which was used for determining the unknown concentrations of nicotine's solutions.

\section{Results and Discussion}

Study of nicotine's adsorption changing on (CACS) at different temperatures

The change of the adsorbed amount of nicotine was measured with the change of the initial concentration after soaking $0.05 \mathrm{~g}$ of the adsorbent material in $5 \mathrm{ml}$ of the prepared nicotine solution for 24 hours at the temperature of (20, $30,35,40^{\circ} \mathrm{C}$ ), The results are shown in tables $(2,3,4,5)$ respectively.

Where $\mathrm{C}_{0}$ : the initial concentration of nicotine solution $(\mathrm{mmol} / \mathrm{l}), \mathrm{C}$ : the equilibrium nicotine concentration $(\mathrm{mmol} / \mathrm{l})$, a: the adsorbed nicotine amount at $(\mathrm{t})$ the time $(\mathrm{mmol} / \mathrm{kg}), \mathrm{t}$ : the time of soaking (h).

Study of the results according to langmuir equation

When representing the previous results diagrammatically according to Langmuir equation axis, the results were shown as in Fig. 3.

It's noticed by Fig. 3 that there is an acceptable

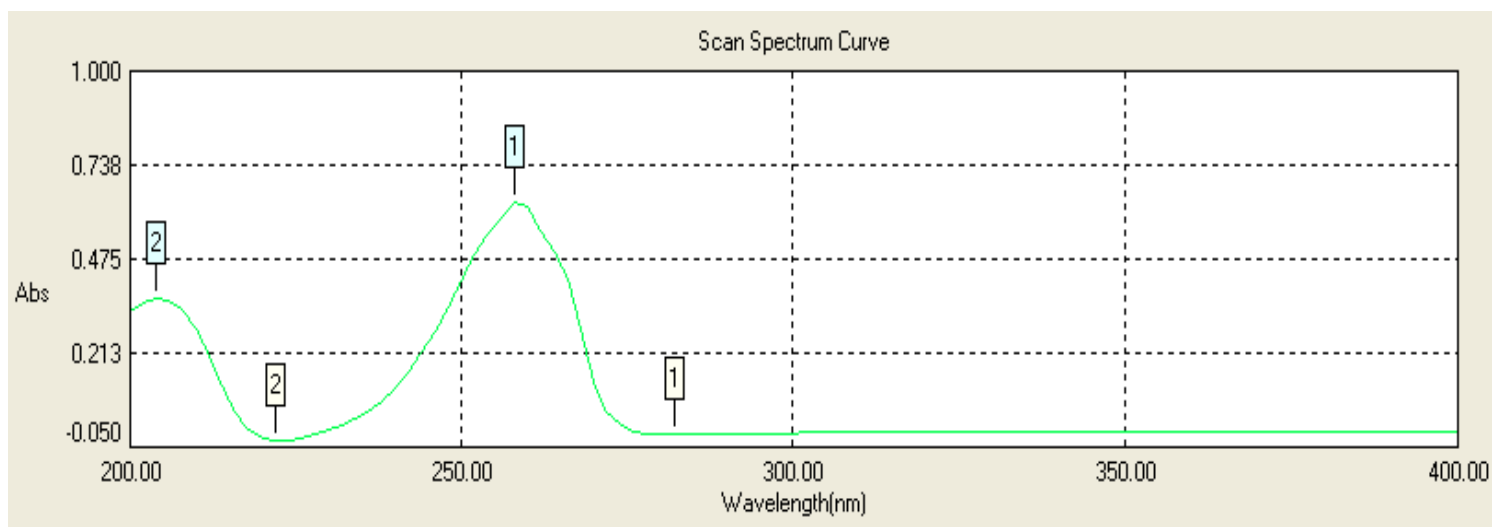

Fig. 1. Spectral scanning for the studied nicotine solution (20ppm).

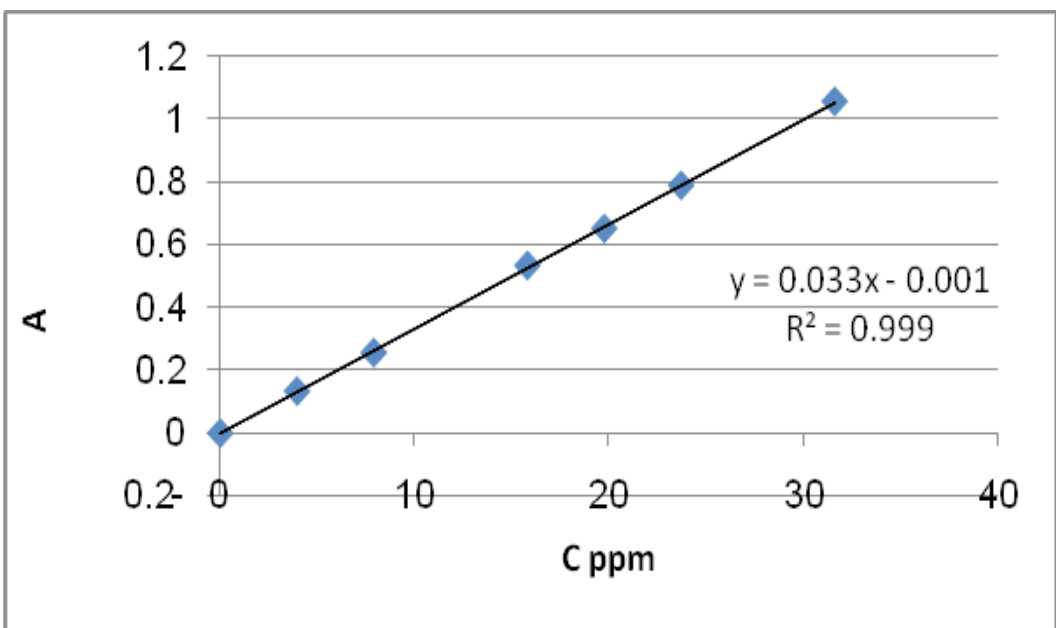

Fig. 2. Change of the solution absorbance with the change of nicotiness solutions concentration. 
TABLE 2. Change of nicotine's equilibrium concentration at $20^{\circ} \mathrm{C}$.

\begin{tabular}{ccccccc}
\hline $\mathbf{C}_{\mathbf{0}}[\mathbf{m m o l} / \mathbf{l}]$ & $\mathbf{C}[\mathbf{m m o l} / \mathbf{l}]$ & $\mathbf{1} / \mathbf{C}$ & $\mathbf{L o g} \mathbf{C}$ & $\mathbf{a}[\mathbf{m m o l} / \mathbf{k g}]$ & $\mathbf{1 / a}$ & $\mathbf{L o g} \mathbf{a}$ \\
\hline 0.642258 & 0.2200443 & 4.544538 & -0.657489 & 41.9132 & 0.02386 & 1.6224 \\
1.360947 & 0.3957716 & 2.526709 & -0.402555 & 96.1538 & 0.01040 & 1.9830 \\
1.831238 & 0.7602933 & 1.315282 & -0.119018 & 106.6321 & 0.00938 & 2.0279 \\
2.418023 & 1.3134245 & 0.761368 & 0.1184051 & 110.3304 & 0.00906 & 2.0427 \\
3.094181 & 1.4257889 & 0.701366 & 0.1540552 & 166.4201 & 0.00601 & 2.2212 \\
3.79068 & 1.8775887 & 0.532598 & 0.2736004 & 191.0750 & 0.00523 & 2.2812 \\
4.373767 & 2.3271079 & 0.429718 & 0.3668165 & 204.6351 & 0.00489 & 2.3110 \\
4.863166 & 2.4546967 & 0.407382 & 0.3899978 & 240.3846 & 0.00416 & 2.3809 \\
5.367357 & 2.8599605 & 0.349655 & 0.4563600 & 250.2465 & 0.00400 & 2.3984 \\
6.300542 & 3.4246794 & 0.291998 & 0.5346199 & 287.4753 & 0.00348 & 2.4586 \\
\hline
\end{tabular}

TABLE 3. Change of nicotine's equilibrium concentration at $30^{\circ} \mathrm{C}$.

\begin{tabular}{ccccccc}
\hline $\mathbf{C}_{\mathbf{0}}[\mathbf{m m o l} / \mathbf{l}]$ & $\mathbf{C}[\mathbf{m m o l} / \mathbf{l}]$ & $\mathbf{1} / \mathbf{C}$ & $\mathbf{L o g} \mathbf{C}$ & $\mathbf{a}[\mathbf{m m o l} / \mathbf{k g}]$ & $\mathbf{1} / \mathbf{a}$ & $\mathbf{L o g} \mathbf{a}$ \\
\hline 0.622596 & 0.13215 & 7.567164 & -0.8789 & 48.6933 & 0.0205 & 1.68747 \\
1.221215 & 0.32205 & 3.105072 & -0.4921 & 89.8669 & 0.0111 & 1.95360 \\
1.993466 & 0.55097 & 1.814968 & -0.2589 & 144.2308 & 0.0069 & 2.15906 \\
2.367233 & 0.96308 & 1.038336 & -0.0163 & 140.4093 & 0.0071 & 2.14740 \\
2.903414 & 1.28637 & 0.777384 & 0.1094 & 161.6741 & 0.0062 & 2.20864 \\
3.905818 & 1.80609 & 0.553682 & 0.2567 & 209.9359 & 0.0048 & 2.32209 \\
4.316629 & 2.07322 & 0.482340 & 0.3166 & 224.2973 & 0.0045 & 2.35082 \\
5.143059 & 2.59868 & 0.384811 & 0.4148 & 259.9852 & 0.0038 & 2.41495 \\
5.489645 & 2.88720 & 0.346356 & 0.4605 & 260.2318 & 0.0038 & 2.41536 \\
6.418885 & 3.64596 & 0.274276 & 0.5618 & 277.2436 & 0.0036 & 2.44286 \\
\hline
\end{tabular}

TABLE 4. Change of nicotine's equilibrium concentration at $35^{\circ} \mathrm{C}$.

\begin{tabular}{ccccccc}
\hline $\mathbf{C}_{\mathbf{0}}[\mathbf{m m o l} / \mathbf{l}]$ & $\mathbf{C}[\mathbf{m m o l} / \mathbf{l}]$ & $\mathbf{1} / \mathbf{C}$ & $\mathbf{L o g} \mathbf{C}$ & $\mathbf{a}[\mathbf{m m o l} / \mathbf{k g}]$ & $\mathbf{1 / a}$ & $\mathbf{L o g} \mathbf{a}$ \\
\hline 0.6466 & 0.1529 & 6.5419 & -0.8157 & 49.3097 & 0.02028 & 1.69293 \\
1.3905 & 0.4037 & 2.4769 & -0.3939 & 98.6193 & 0.01014 & 1.99396 \\
1.8664 & 0.6974 & 1.4340 & -0.1565 & 116.4941 & 0.00858 & 2.06630 \\
2.4350 & 1.1346 & 0.8814 & 0.0548 & 129.9926 & 0.00769 & 2.11392 \\
2.8809 & 1.3140 & 0.7610 & 0.1186 & 156.5582 & 0.00639 & 2.19468 \\
3.7367 & 1.6556 & 0.6040 & 0.2189 & 207.7170 & 0.00481 & 2.31747 \\
4.4824 & 2.1040 & 0.4753 & 0.3231 & 237.3028 & 0.00421 & 2.37530 \\
4.7592 & 2.4788 & 0.4034 & 0.3942 & 227.9956 & 0.00439 & 2.35793 \\
5.4228 & 2.9951 & 0.3339 & 0.4764 & 242.7268 & 0.00412 & 2.38512 \\
6.0645 & 3.4763 & 0.2877 & 0.5411 & 258.8141 & 0.00386 & 2.41299 \\
\hline
\end{tabular}

Egypt. J. Chem. 61, No. 6 (2018) 
TABLE 5. Change of nicotine's equilibrium concentration at $40^{\circ} \mathrm{C}$.

\begin{tabular}{ccccccc}
\hline $\mathbf{C}_{\mathbf{0}}[\mathbf{m m o l} / \mathbf{l}]$ & $\mathbf{C}[\mathbf{m m o l} / \mathbf{l}]$ & $\mathbf{1 / C}$ & $\mathbf{L o g} \mathbf{C}$ & $\mathbf{a}[\mathbf{m m o l} / \mathbf{k g}]$ & $\mathbf{1 / a}$ & $\mathbf{L o g} \mathbf{~ a}$ \\
\hline 0.6226 & 0.1100 & 9.0891 & -0.9585 & 51.2204 & 0.0195 & 1.7094 \\
1.2212 & 0.3091 & 3.2351 & -0.5099 & 91.1612 & 0.0110 & 1.9598 \\
1.9935 & 0.5560 & 1.7987 & -0.2550 & 143.7377 & 0.0070 & 2.1576 \\
2.3672 & 0.9410 & 1.0628 & -0.0264 & 142.6282 & 0.0070 & 2.1542 \\
2.9034 & 1.4504 & 0.6894 & 0.1615 & 145.2786 & 0.0069 & 2.1622 \\
3.9058 & 1.9509 & 0.5126 & 0.2902 & 195.4512 & 0.0051 & 2.2910 \\
4.3166 & 2.1900 & 0.4566 & 0.3404 & 212.6479 & 0.0047 & 2.3277 \\
5.1431 & 2.7494 & 0.3637 & 0.4392 & 239.3368 & 0.0042 & 2.3790 \\
5.4896 & 3.0570 & 0.3271 & 0.4853 & 243.3432 & 0.0041 & 2.3862 \\
6.4189 & 3.5942 & 0.2782 & 0.5556 & 282.4211 & 0.0035 & 2.4509 \\
\hline
\end{tabular}

Where C0: the initial concentration of nicotine solution (mmol/l), C: the equilibrium nicotine concentration (mmol/l), a: the adsorbed nicotine amount at $(\mathrm{t})$ the time $(\mathrm{mmol} / \mathrm{kg})$, $\mathrm{t}$ : the time of soaking $(\mathrm{h})$.

conformance of the results with Langmuir equation (1):

$\theta=\mathrm{a} / \mathrm{a}_{\mathrm{m}}=\left(\mathrm{K}_{\mathrm{L}} \mathrm{C}\right) \quad /\left(1+\mathrm{K}_{\mathrm{L}} \mathrm{C}\right) \Longrightarrow \mathrm{a}$

$=\left(\mathrm{K}_{\mathrm{L}} \mathrm{a}_{\mathrm{m}} \mathrm{C}\right) /\left(1+\mathrm{K}_{\mathrm{L}} \mathrm{C}\right)$

$1 / \mathrm{a}=1 /\left(\mathrm{K}_{\mathrm{L}} \mathrm{a}_{\mathrm{m}} \mathrm{C}\right)+1 / \mathrm{a}_{\mathrm{m}}$

Where $\mathrm{C}$ : the equilibrium concentration of the solution $(\mathrm{mmol} / \mathrm{L})$, a: the adsorbed nicotine amount $(\mathrm{mmol} / \mathrm{kg}), \mathrm{a}_{\mathrm{m}}$ : the amount of the adsorbed material that is retained on the adsorbent when it forms a monolayer $(\mathrm{mmol} / \mathrm{kg}), \mathrm{K}_{\mathrm{L}}$ : Langmuir's adsorption coefficient ( $\left.\mathrm{L} . \mathrm{mmol}^{-1}\right)$, the values of the adsorption dimensions according to Langmuir equation at the studied temperature are shown in Table 6.

Comparison with the results of other works

In 2014 Basher verified the adsorption of nicotine from the aqueous solutions by using coconut fiber, sawdust and tea leaves wastes as adsorbent materials, where he studied the effect of the contact time and the amount of the adsorbent materials. All the experiments were applied at 30 ${ }^{\circ} \mathrm{C}$, it was noticed that the highest removal at the optimal conditions was verified for coconut fiber and sawdust, while it was less removal for tea leaves wastes [2].

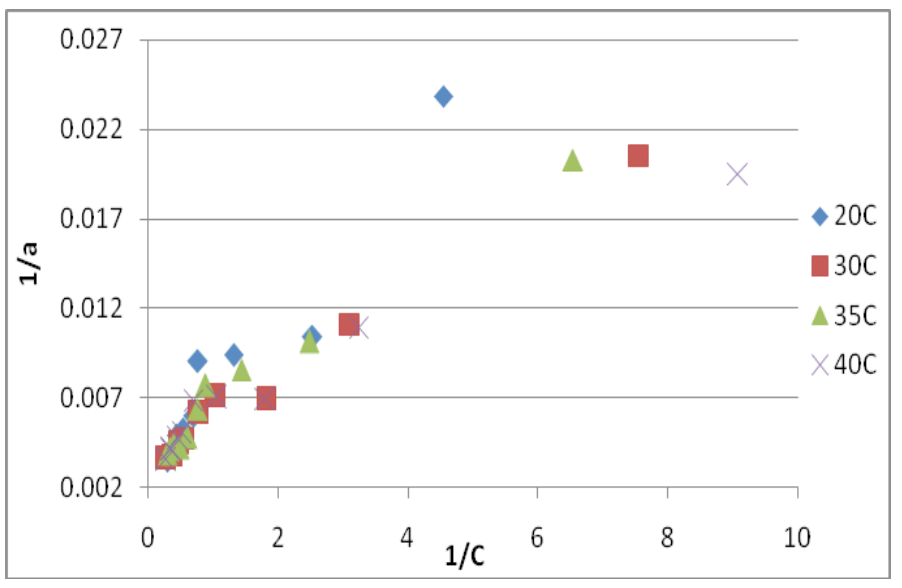

Fig. 3. Change of nicotine's equilibrium concentration according to Langmuir equation axis at the studied temperatures.

When comparing the results in Table 7 with those presented in Table 6 of this study, a higher adsorption of nicotine is observed on the coffee carbon sample (CACS) that modified with oleum.
Study of the results according to Freundilch equation

The results are shown in Fig. 4 when representing the previous experimental data diagrammatically according to Freundlich equation axis. 
TABLE 6. Values of the adsorption dimensions according to Langmuir equation at the studied temperature.

\begin{tabular}{cccc}
\hline Temperature $\left(\mathbf{C}^{0}\right)$ & $\mathbf{K}_{\mathbf{L}}$ & $\mathbf{a}_{\mathbf{m}}[\mathbf{m m o l} / \mathbf{k g}]$ & $\mathbf{R}^{2}$ \\
\hline 20 & 0.6744 & 344.82 & 0.930 \\
30 & 1.5217 & 285.71 & 0.983 \\
35 & 1.4615 & 263.15 & 0.972 \\
40 & 2.4705 & 238.09 & 0.966 \\
\hline
\end{tabular}

TABLE 7. Best adsorbed amounts of nicotine on the studied adsorbent materials [2].

\begin{tabular}{ccc}
\hline Adsorbent & $\mathbf{a}_{\mathbf{m}}[\mathbf{m g} / \mathbf{g}]$ & $\mathbf{a}_{\mathbf{m}}[\mathbf{m m o l} / \mathbf{k g}]$ \\
\hline Coconut fiber & 2.04 & 12.5 \\
Sawdust & 1.88 & 11.5 \\
Tea leaves waste & 0.80 & 4.9
\end{tabular}

It is noticed by Fig. 4 that there is an acceptable applicability of Freundlich equation when the initial concentration of the nicotine change in the solution. Ghiaci expressed Freundlich equation (2) $[10]:$

$$
\begin{aligned}
a & =K_{f} \cdot C^{1 / n} \\
\log a & =1 / n \log C+\log K_{f}
\end{aligned}
$$

Where $C$ : the equilibrium concentration of the solution $(\mathrm{mmol} / \mathrm{L})$, a: the adsorbed nicotine amount (mmol/kg), $\mathrm{K}_{\mathrm{f}}$, n: Freundlich coefficients, the values of the adsorption dimensions according to Freundlich equation at the studied temperature are shown in Table 8.

It is also noticed by the previous Tables 6,8 that there is a good value of the correlation coefficient $\mathrm{R}^{2}$ which means that all the equations represented diagrammatically are acceptable at the studied temperatures. That indicates a conformance of the experimental data with Langmuir and Freundlich equations at all temperatures.

The study of the kinetics of nicotine's adsorption on the modified coffee carbon with the change of time

The change of the equilibrium concentration of the adsorbed nicotine according to the contact time

The change of nicotine's concentration was studied after soaking $0.05 \mathrm{~g}$ of the adsorbent material in $5 \mathrm{ml}$ of nicotine's solution at different times, Fig. 5 shows the change of the equilibrium concentration of the compressed coffee carbon sample (CACS) with the change of time.

Figure 5 shows that the first order rate

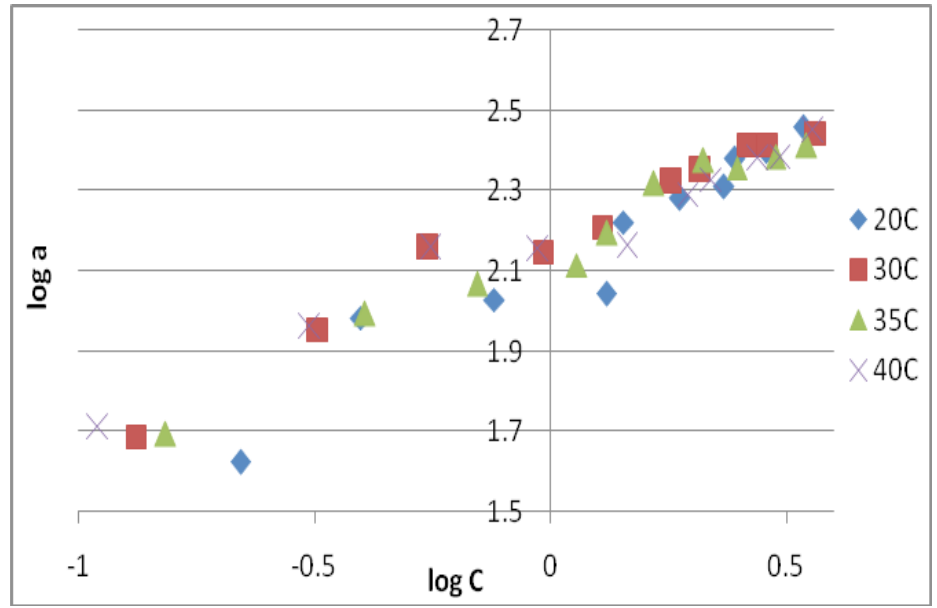

Fig. 4. Change of nicotine's equilibrium concentration according to Freundlich equation axis at the studied temperatures

Egypt. J. Chem. 61, No. 6 (2018) 
TABLE 8. The values of the adsorption dimensions according to Freundlich equation at the studied temperatures.

\begin{tabular}{cccc}
\hline Temperature $\left(\mathbf{C}^{0}\right)$ & $\mathbf{K}_{\mathrm{f}}\left(\mathbf{l i t} \mathbf{1}^{\mathbf{n} / \mathbf{n}}\left[\mathbf{k g} \cdot(\mathbf{m m o l})^{(1-\mathrm{n}) / \mathrm{n}}\right]\right)$ & $\mathbf{n}$ & $\mathbf{R}^{2}$ \\
20 & 126.67 & 1.592 & 0.926 \\
30 & 153.53 & 1.9704 & 0.966 \\
35 & 141.48 & 1.885 & 0.969 \\
40 & 149.41 & 2.229 & 0.958 \\
\hline
\end{tabular}

constant of the interaction of nicotine is a result of the unconformity of the experimental data with the equation (3): $\mathrm{Ln}_{0} / \mathrm{C}=\mathrm{kt}$

where $\mathrm{C}_{0}$ : the initial concentration of nicotine solution $(\mathrm{mmol} / \mathrm{l}), \mathrm{C}$ : the equilibrium concentration of nicotine $(\mathrm{mmol} / \mathrm{l})$, $\mathrm{t}$ : the time of soaking (hour), k: the interaction's speed coefficient $\left(\mathrm{h}^{-1}\right)$.

The change of nicotine's equilibrium concentration with the change of time according to The pseudo first-order and pseudo secondorder models

The adsorbed amount of nicotine was studied with the change of time in the same previous conditions, the data are shown in Table 9 according to both pseudo first-order and pseudo second-order equations.

Here $a_{e}=287.475 \mathrm{mmol} / \mathrm{kg}$ is the adsorbed nicotine amount at the equilibrium stage, a: the adsorbed nicotine amount at $(\mathrm{t})$ the time (mmol/ $\mathrm{kg}), \mathrm{C}_{0}$ : the initial concentration of nicotine solution $(\mathrm{mmol} / \mathrm{l}), \mathrm{C}$ : the equilibrium nicotine concentration $(\mathrm{mmol} / \mathrm{l})$, t: the time of soaking $(\mathrm{h})$.

When applying the pseudo first-order model for studying the kinetics of adsorption according to Lagergren equation (4) [11]:

$$
\operatorname{Ln}\left(\mathrm{a}_{\mathrm{e}}-\mathrm{a}\right)=\operatorname{Ln} \mathrm{a}_{1 \mathrm{e}}-\mathrm{k}_{1} \mathrm{t}
$$

Where $\mathrm{k}_{1}$ is the kinetics constant of the pseudo first-order $\left(\mathrm{h}^{-1}\right), \mathrm{a}_{1 \mathrm{e}}$ : the theoretical amount of the adsorbed nicotine according to the pseudo first-order, Fig. 6 clarifies the change of $\operatorname{Ln}\left(\mathrm{a}_{\mathrm{e}}-\mathrm{a}\right)$ with the change of the contact time according to Lagergren equation.

When applying the pseudo second-order model for studying the kinetics of the interaction according to equation (5) [12].

$$
\mathrm{t} / \mathrm{a}=1 /\left(\mathrm{k}_{2} \mathrm{a}_{2 \mathrm{e}}^{2}\right)+\left(1 / \mathrm{a}_{2 \mathrm{e}}\right) \mathrm{t}
$$

Where $\mathrm{k}_{2}$ : kinetics constant of the pseudo second-order $\left(\mathrm{kg} \cdot \mathrm{mmol}^{-1} \cdot \mathrm{h}^{-1}\right), \mathrm{a}_{2 \mathrm{e}}$ : the theoretical amount of adsorbed nicotine according to the

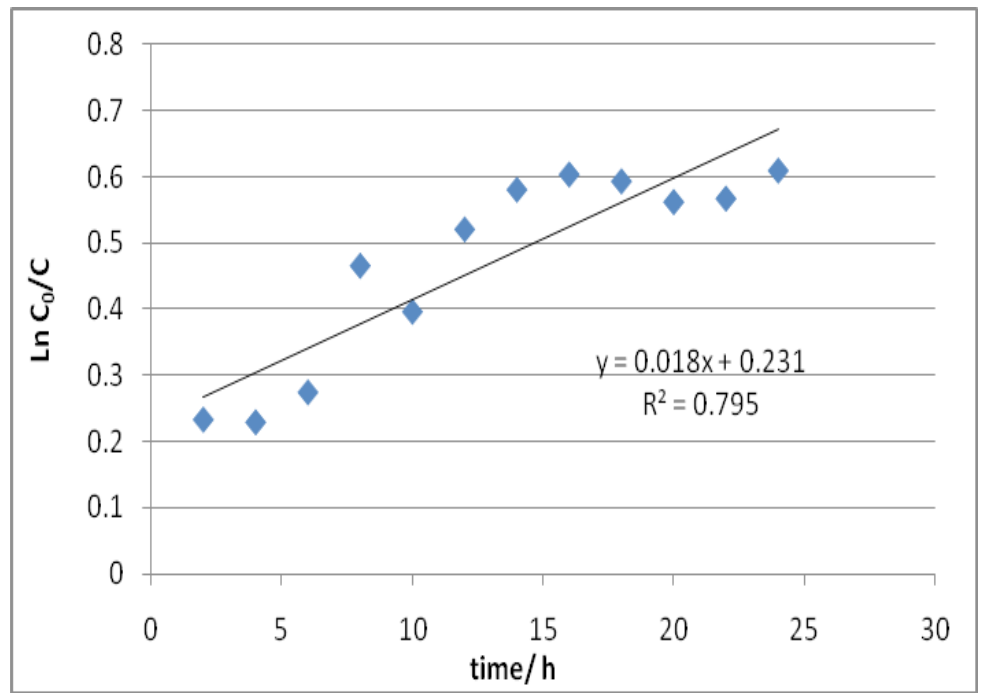

Fig.5. Change of the equilibrium concentration of nicotine with the change of time. 
TABLE 9. Change of adsorbed nicotine amount with the change of time

\begin{tabular}{cccccc}
\hline $\mathbf{t}(\mathbf{h})$ & $\mathbf{C}_{\mathbf{0}}[\mathbf{m m o l} / \mathbf{l}]$ & $\mathbf{C}[\mathbf{m m o l} / \mathbf{l}]$ & $\mathbf{a}[\mathbf{m m o l} / \mathbf{k g}]$ & $\mathbf{L n}\left(\mathbf{a}_{\mathbf{e}} \mathbf{- a}\right)$ & $\mathbf{t} / \mathbf{a}$ \\
\hline 2 & 6.1534 & 4.8701 & 128.205 & 5.0708 & 0.0156 \\
4 & 6.4361 & 5.1135 & 131.903 & 5.0473 & 0.0303 \\
6 & 6.4361 & 4.8886 & 154.709 & 4.8888 & 0.0388 \\
8 & 5.7994 & 3.6386 & 216.038 & 4.2692 & 0.0370 \\
10 & 6.6280 & 4.4572 & 216.963 & 4.2561 & 0.0461 \\
12 & 6.4448 & 3.8277 & 261.341 & 3.2642 & 0.0459 \\
14 & 6.2272 & 3.4836 & 274.285 & 2.5814 & 0.0510 \\
16 & 5.8732 & 3.2107 & 265.656 & 3.0839 & 0.0602 \\
18 & 5.8732 & 3.2438 & 262.574 & 3.2159 & 0.0686 \\
20 & 6.3009 & 3.5905 & 270.587 & 2.8281 & 0.0739 \\
22 & 6.3009 & 3.5720 & 272.867 & 2.6833 & 0.0806 \\
24 & 6.3009 & 3.4247 & 287.475 & - & 0.0835 \\
\hline
\end{tabular}

Here $\mathrm{ae}=287.475 \mathrm{mmol} / \mathrm{kg}$ is the adsorbed nicotine amount at the equilibrium stage, a: the adsorbed nicotine amount at $(\mathrm{t})$ the time $(\mathrm{mmol} / \mathrm{kg}), \mathrm{C} 0$ : the initial concentration of nicotine solution $(\mathrm{mmol} / \mathrm{l}), \mathrm{C}$ : the equilibrium nicotine concentration $(\mathrm{mmol} / \mathrm{l})$, t: the time of soaking $(\mathrm{h})$.

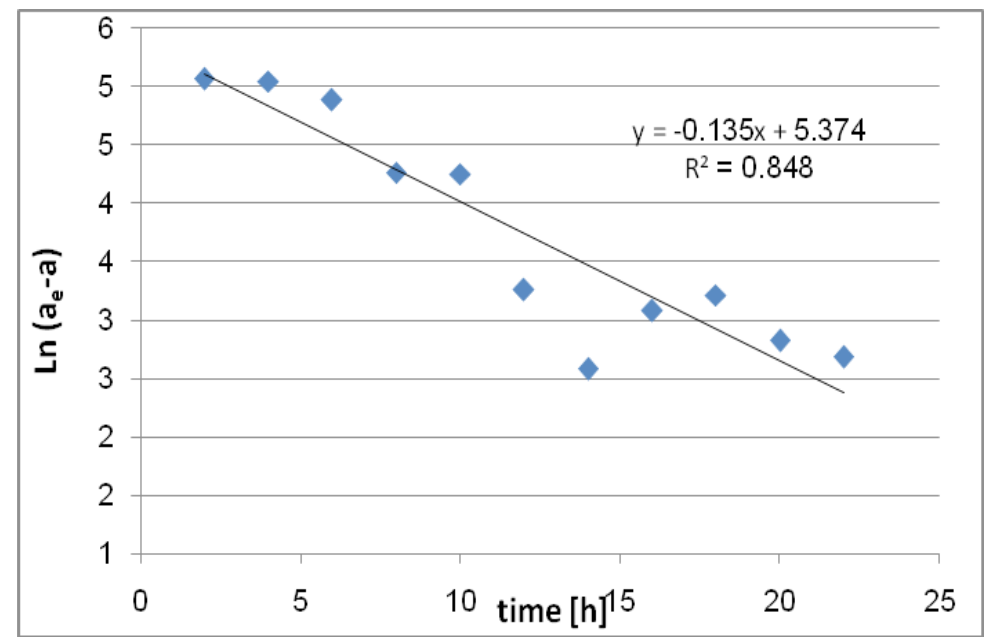

Fig.6. Change of Ln (ae-a) with the change of the contact time.

pseudo second -order, Fig. 7 clarifies the change of t/a with the change of the contact time according to equation (5) [12].

It is noticed in Fig.6 that there is not sufficient conformity of the pseudo first-order model according to Lagergren equation because of the decreasing in $\mathrm{R}^{2}$ value, whereas It is noticed in Fig. 7 that there is good conformity of the pseudo second-order model according to equation (5), where $\mathrm{a}_{2 \mathrm{e}}=344.82 \mathrm{mmol} / \mathrm{kg}$ and $\mathrm{k}_{2}=0.000556$ $\mathrm{kg} \cdot \mathrm{mmol}^{-1} \cdot \mathrm{h}^{-1}$.
Determining the thermodynamic parameters for the surface interaction

The change of Gibbs free energy was calculated by use of Langmuir constants at each one of the studied temperature:

$$
\Delta \mathrm{G}^{0}=-\mathrm{RTLnK}_{\mathrm{L}}
$$

The equation of Arrhenius was used to calculate the change of interaction's enthalpy:

$$
\operatorname{Ln} K_{L}=\left(-\Delta H^{0} / R T\right)+\operatorname{Ln} A
$$




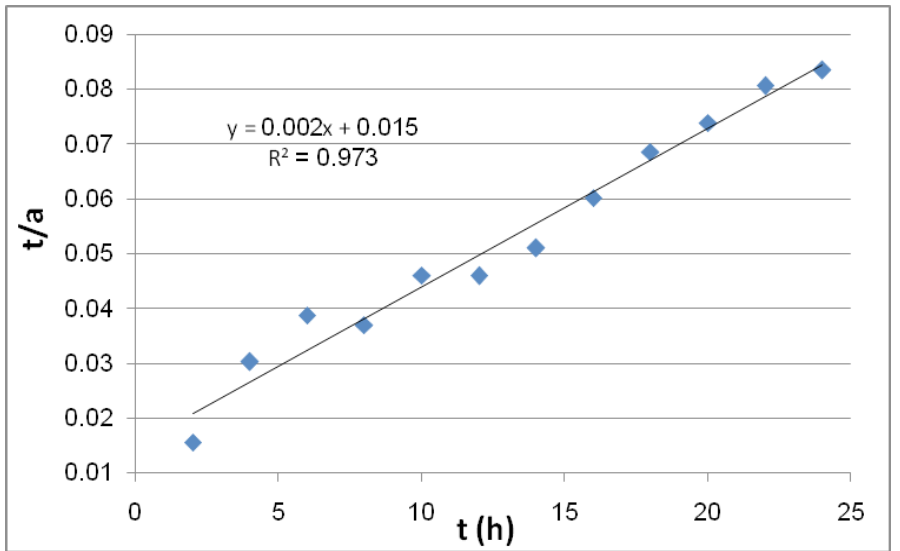

Fig. 7. Change of $t / a$ with the change of the contact time.

The change of entropy was calculated as well by the equation after calculating $\Delta \mathrm{H}^{0}$ and $\Delta \mathrm{G}^{0}$ :

$$
\Delta \mathrm{S}^{0}=\left(\Delta \mathrm{H}^{0}-\Delta \mathrm{G}^{0}\right) / \mathrm{T}
$$

Where $\mathrm{R}=1.987 \mathrm{Cal} \cdot \mathrm{K}^{-1} \cdot \mathrm{mol}^{-1}$, the results are shown in Table 10.

Ln $\mathrm{K}_{\mathrm{L}}$ was represented diagrammatically with the change of temperature for determining the change of the interaction enthalpy in Fig. 8.

It is clear by Fig. 8 that there is an applicability of Langmuir equation which describes an isothermal adsorption of molecules connecting with active sites presuming that the adsorbent surface is homogeneous, the enthalpy change is $\Delta \mathrm{H}=11013.56 \mathrm{Cal} / \mathrm{mol}$, thereby, the interactions are endothermic and the adsorption is of chemical nature.

Results of the spectroscopy study

The infrared spectrum (FT-IR) of the compressed coffee carbon (CAC) was studied and the results of the spectrum were shown in Fig.9.

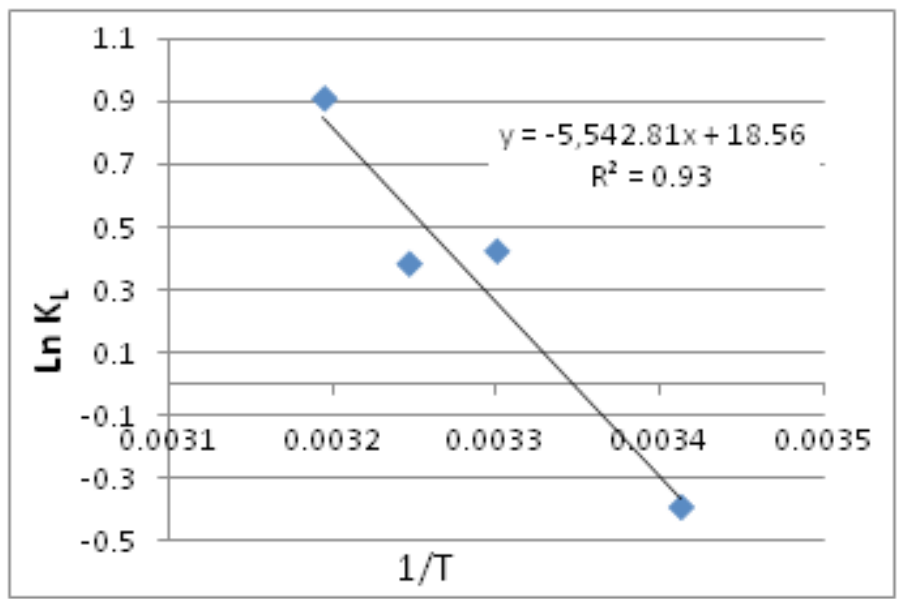

Fig. 8. Change of Ln KL with the change of temperature.

TABLE 10. Thermodynamic parameters of nicotine's adsorption on the surface of (CACS).

\begin{tabular}{cccccc}
\hline $\mathbf{T}\left(\mathbf{C}^{\mathbf{0}}\right)$ & $\mathbf{1} / \mathbf{T}$ & $\mathbf{K}_{\mathbf{L}}$ & $\mathbf{L n ~ \mathbf { K } _ { \mathbf { L } }}$ & $\Delta \mathbf{G}^{\mathbf{0}} \mathbf{c a l} / \mathbf{m o l}$ & $\begin{array}{c}\Delta \mathbf{S}^{\mathbf{0}} \\
\mathbf{c a l} / \mathbf{m o l}^{\mathbf{0}} \mathbf{\mathbf { K } ^ { \mathbf { 0 } }}\end{array}$ \\
\hline 20 & 0.003401 & 0.6744 & -0.3939 & 229.343 & 36.8062 \\
30 & 0.003300 & 1.5217 & 0.41982 & -252.762 & 37.1825 \\
35 & 0.003246 & 1.4615 & 0.37946 & -232.23 & 36.5123 \\
40 & 0.003194 & 2.4705 & 0.90442 & -562.487 & 36.9841 \\
\hline
\end{tabular}


Table 11 clarifies the effective functional groups that belong to the peaks shown in Fig. 9 in addition to the wave number and intensity of each one of them. That is, before the modification with oleum, carbon and nitrogen groups may be related to the presence of organic compounds i.e. (proteins, glucose) in the chemical composition of coffee [13].

In the case of Compressed coffee carbon produced after modifying it with oleum, new peaks appeared in the spectrum (FT-IR) shown in Fig. 10.

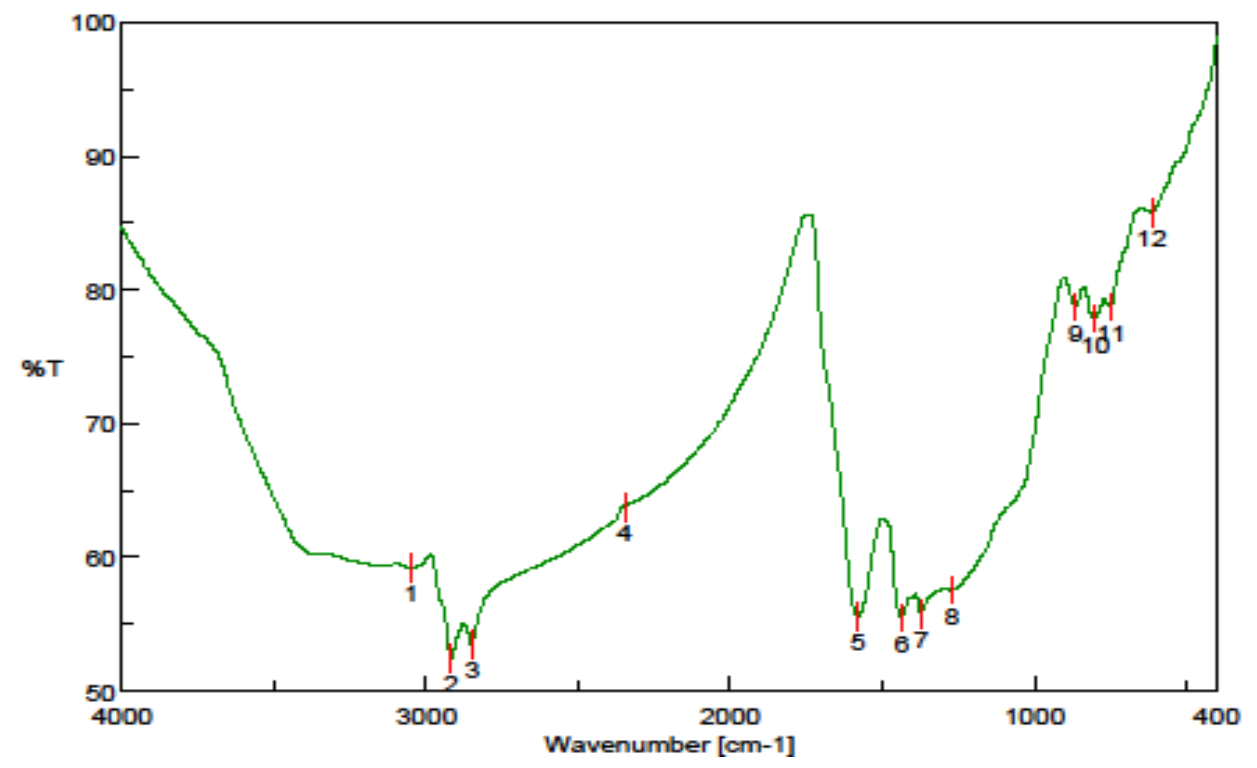

Fig. 9. FT-IR spectrum of Compressed coffee carbon (CAC).

TABLE 11. Effective functional groups in FT-IR spectrum of (CAC) [14].

\begin{tabular}{cccc}
\hline Group & Number & Wave number $\mathbf{~ m}^{-\mathbf{1}}$ & Intensity \% \\
$\mathrm{C}-\mathrm{H}$ & 2 & 2917.77 & 5.24 \\
& 3 & 2850.27 & 5.35 \\
$\mathrm{NO}^{+}$ & 4 & 2345.98 & 6.37 \\
$\mathrm{C}=\mathrm{N}$ & 5 & & 5.56 \\
$\mathrm{C}=\mathrm{C}$ & & 1579.41 & \\
& & & 5.58 \\
$\mathrm{NO}_{2}^{+}$ & 7 & 1372.10 & \\
& & & 5.58 \\
$\mathrm{NO}_{2}^{-}$ & 7 & 1372.10 & 7.78 \\
$\mathrm{NO}_{3}^{-}$ & 10 & 800.31 & \\
\hline
\end{tabular}

Table 12 clarified the effective functional groups $\left(-\mathrm{SO}_{2}-, \mathrm{RSO}_{3} \mathrm{H}, \mathrm{SO}_{4}^{2-}\right.$ and $\left.\mathrm{S}=\mathrm{O}\right)$ that indicate the modification of carbon's surface with oleum, these peaks are absent in the FT-IR spectrum of Compressed coffee carbon untreated with oleum, the nitrogen groups may belong to the original sample composition.

Figure 11 shows the spectrum of the adsorption of nicotine on (CACS) surface.

Groups $\mathrm{C}=\mathrm{N}, \mathrm{C}=\mathrm{C}$ and $\mathrm{C}-\mathrm{H}$ bond of the 


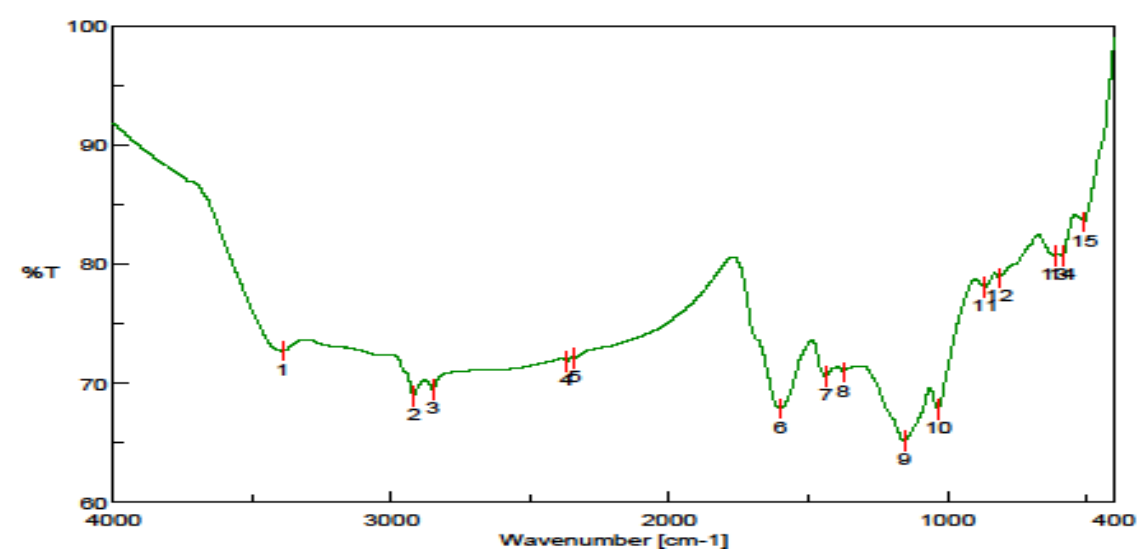

Fig.10. FT-IR spectrum of (CACS).

TABLE 12. Effective functional groups in FT-IR spectrum of (CACS) [14].

\begin{tabular}{cccc}
\hline Group & Number & Wave number $\mathbf{c m}^{-\mathbf{1}}$ & Intensity $\%$ \\
\hline $\mathrm{N}-\mathrm{H}$ & 1 & 3394.1 & 7.27 \\
$\mathrm{C}-\mathrm{H}$ & 2 & 2920.66 & 6.89 \\
& 3 & 2851.24 & 6.94 \\
$\mathrm{NO}^{+}$ & 4 & 2369.12 & 7.18 \\
$\mathrm{C}=\mathrm{O}$ & 6 & 1600.63 & 6.78 \\
$\mathrm{NO}_{2}^{+}$ & 8 & 1374.03 & 6.78 \\
$\mathrm{NO}_{2}^{-}$ & 8 & 1374.03 & 6.78 \\
$\mathrm{NO}_{3}^{-}$ & 12 & 814.77 & 7.88 \\
$\mathrm{RSO}_{3}^{-} \mathrm{H}$ & 10 & 1032.69 & 6.78 \\
$\mathrm{~S}^{-}$ & & & \\
$\mathrm{RSO}_{3} \mathrm{H}$ & 13 & 614.21 & 8.07 \\
$\mathrm{SO}_{4}^{2-}$ & 14 & 587.21 & 8.07 \\
$-\mathrm{SO}_{2-}^{-}$ & & & \\
\hline
\end{tabular}

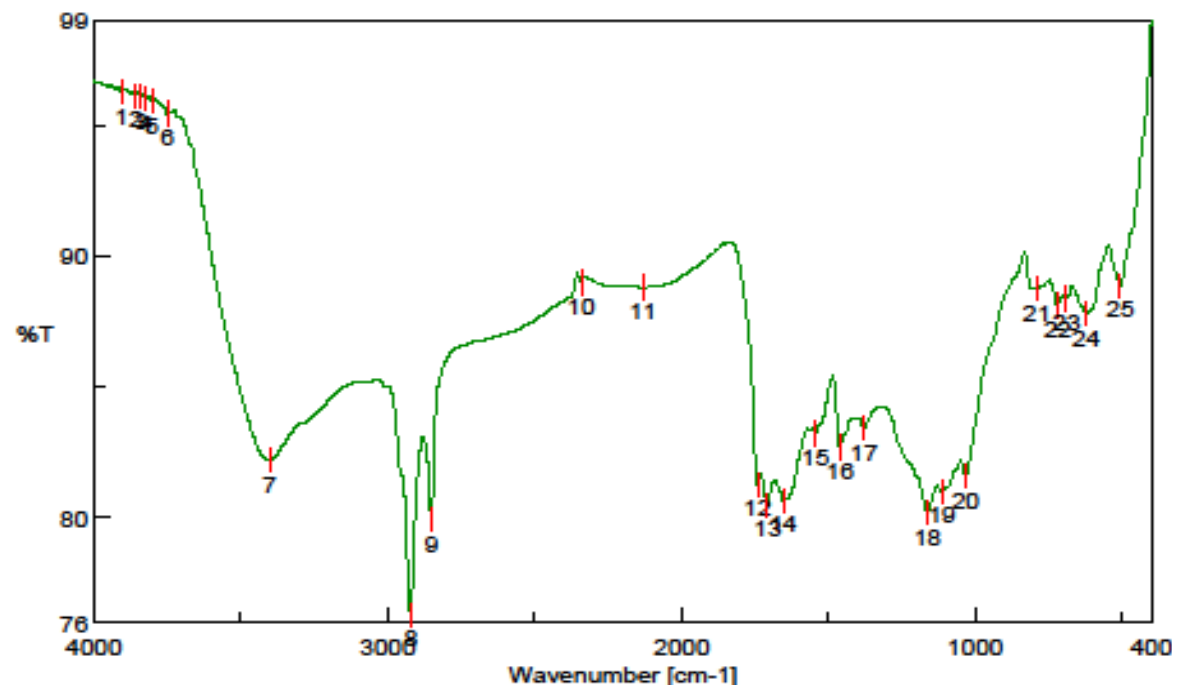

Fig. 11. FT-IR spectrum of (CACS) and the adsorbed nicotine on its surface.

Egypt. J. Chem. 61, No. 6 (2018) 
monosubstituted pyridinic cycle in the nicotine molecule that are shown in Table 13 indicate the presence of a nicotine molecule $\left(\mathrm{C}_{10} \mathrm{H}_{14} \mathrm{~N}_{2}\right)$ adsorbed on the surface of carbon modified with oleum (CACS), the existence of the $\mathrm{RSO}_{3} \mathrm{H}$ group is an evidence for a hydrogen correlation between the nitrogen of the nicotine molecule and the hydrogen on the sulfonated surface.

Mechanism of the adsorption of nicotine on (CACS)

The spectral study enabled the assumption of the mechanism of nicotine molecules adsorption.

The detailed format of nicotine signifies that the two atoms of nicotine are the base of the process of adsorption when considering it as an alkaline molecule, where the ionization constant of the quintet berouliden cycle is $\left(\mathrm{pK}_{\mathrm{a}}=8.02\right)$ which is considered to be more alkaline than the sextet cycle that has an ionization constant of $\left(\mathrm{pK}_{\mathrm{a}}=\right.$ 3.12) as it is shown in the Fig. 12.

The two atoms of nitrogen connect with the protons of (CACS) surface by hydrogen bonds.

TABLE 13. Effective functional groups in FT-IR spectrum of (CACS) and the adsorbed nicotine on its surface [14]

\begin{tabular}{cccc}
\hline Group & Number & Wave number $\mathbf{~ m}^{-1}$ & Intensity $\%$ \\
\hline $\mathrm{N}-\mathrm{H}$ & 7 & 3401.82 & 8.22 \\
& 8 & 2922.59 & 7.63 \\
$\mathrm{C}-\mathrm{H}$ & 9 & 2852.2 & 7.99 \\
& 10 & 2342.12 & 8.90 \\
$\mathrm{NO}^{+}$ & 13 & 1706.69 & 8.05 \\
& 14 & 1653.66 & 8.07 \\
$\mathrm{C}=\mathrm{O}$ & & 1653.66 & 8.07 \\
& 14 & & \\
$\mathrm{C}=\mathrm{N}$ & & 1379.82 & 8.34 \\
$\mathrm{C}=\mathrm{C}$ & & \\
$\mathrm{NO}_{2}^{-}$ & 17 & 1162.87 & 8.02 \\
$\mathrm{NO}_{3}^{-}$ & 18 & 1032.69 & 8.16 \\
$\mathrm{RSO}_{3}{ }^{-}$ & 20 & 1114.65 & 8.10 \\
$\mathrm{HSO}_{4}^{-}$ & 19 & 622.89 & 8.78 \\
$\mathrm{SO}_{4}^{2-}$ & 24 & 790.67 & 8.87 \\
& 21 & 720.28 & 8.81 \\
$\mathrm{C}^{-}-\mathrm{H}$ & 22 & &
\end{tabular}

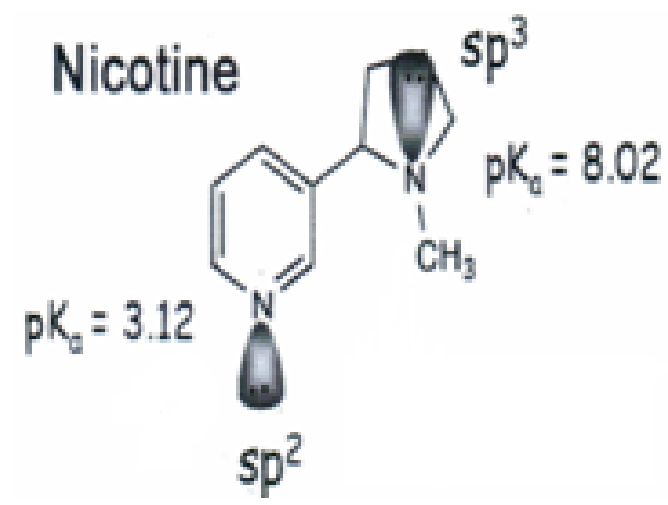

Fig. 12. Nicotine molecular. 
The atom of nitrogen unconnected with the group $-\mathrm{CH}_{3}$ is the most effective because of its connection with $\mathbb{R}$ bonds in the part of pyridine of nicotine.

Since the bipolar torque of nicotine's molecule equals 2.62 Debye [15], the mechanism of adsorption is as in Fig. 13.

Where the adsorption of the nicotine molecule is on Bronsted sites (proton donor) located on (CACS) surface.

Those factors represent the adsorption of a polar material on a polar surface.

\section{Conclusions}

The adsorbed amounts of nicotine were determined by measuring the change of its initial concentration at different temperatures spectrophotometrically, it was noticed that the increase of adsorbed amounts correlate with the increase of initial concentrations at each temperature, where the two equations of Langmuir and Freundlich were corresponded for all of the studied temperatures. The order of the surface interaction was determined according to pseudo second-order model.

The spectral study (FT-IR) of the sample before and after modifying it with oleum and after the

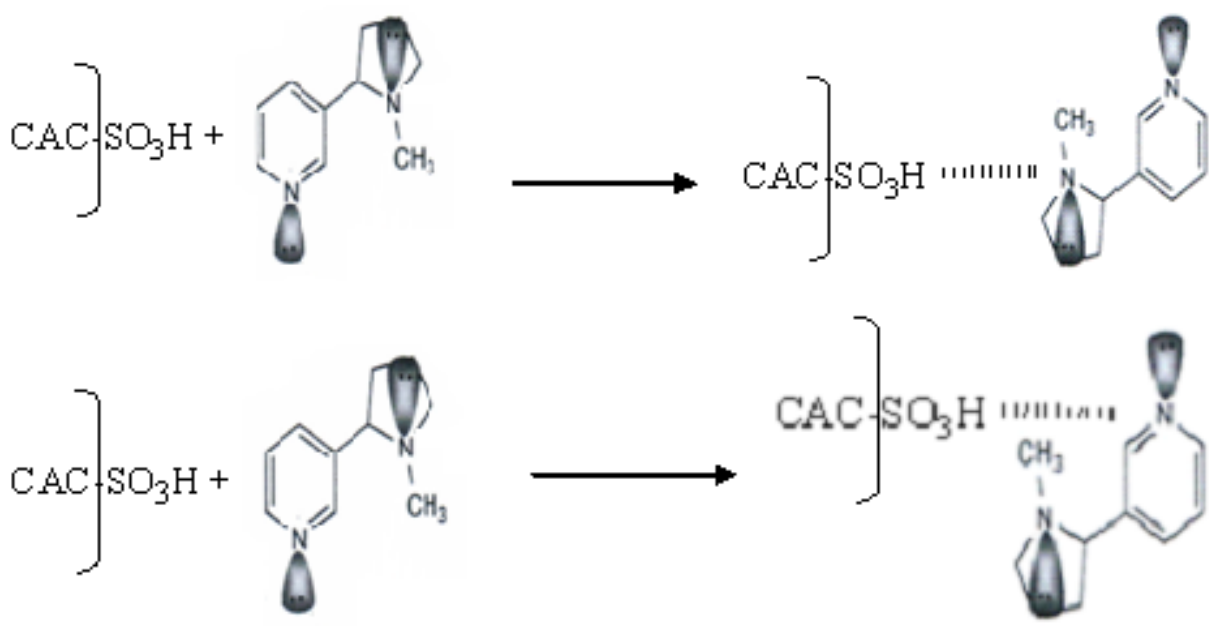

Fig. 13. Mechanism of nicotine adsorption.

adsorption of nicotine on its modified surface and the appearance of new peaks indicated the influence of modification of the (CAC) with oleum on the nicotine adsorption on its surface.

\section{References}

1. Rakic V., Damjanovic L., Rac V., Stosic D., Dondur V., Auroux A., The adsorption of nicotine from aqueous solutions on different zeolite structures. Water Research, 44, 2047- 2057 (2010).

2. Basher Z., Gupta A. K., Chattre A., Adsorption isotherm of separation of nicotine in tobacco products by low cost adsorbents. IOSR Journal of Applied Physics, 3 (3), 39-45 (2014).

3. Maduro R. M., Aznar M., Liquid-liquid equilibrium of ternary systems containing nicotine. Fluid Phase Equilib. 259, Issue 1, SPEC. ISS. 83-88 (2007).
4. Novotny T. E., Zhao F., Consumption and production waste: Another externality of tobacco use. Tob. Control, 8, 75-80 (1999).

5. Grozdanic N., Calado M., Kijevcanin M., Šerbanovic S., Visak Z., Aqueous nicotine solutions: $\mathrm{pH}$ measurements and salting-out effects-analysis of the effective Gibbs energies of hydration and ionic strengths of the solutions, Serb. Chem. Soc. 79 (7), 829-842 (2014).

6. Basher Z., Gupta A. K., Chattre A., Adsorption capacity of nicotine from tobacco products by different adsorbents. International Journal of Computational Engineering Research, 03 (11), (2013).

7. Utomo H. D., The adsorption of heavy metals by waste tea and coffee residues (Thesis, Doctor of Philosophy). University of Otego. Retrieved from http://hdl.handle.net/10523/159 (2007). 
8. 8. Azouaou N., Sadaoui Z., Mokaddem H., Removal of lead from aqueous solution onto untreated coffee grounds: A fixed-bed column study. Chemical Engineering Transactions, 38, 151-156 (2014). DOI: 10.3303/CET1438026.

9. Bezreh W. Y., Shaheen A. A., Study on the adsorption properties of adsorbents for nicotine prepared starting from Syrian Raw materials. $A$ Master Degree Dissertation, Damascus university, Patent No 5044 Syria (2000).

10. Ghiaci E. M., Abbaspur A., Kia R., Seyedeyn-Azad F., Equilibrium isotherm studies for the sorption of benzene, toluene, and phenol onto organo-zeolites and as-synthesized. MCM-41. Sep. Purif. Technol. 40, 217-229 (2004).

11. Lagergren S., About the theory of So-called adsorption of soluble substances. Kung Vetensk.
Acad. Hand. 24, 1-39 (1998).

12. Ho Y. S., Me Kay G., The kinetics of sorption of divalent metal ions onto sphagnum moss peat. Water Res. 34(3), 735-742 (2000).

13. Mussatto S. I., Machado E. M., Martins S., Teixeira A. J., Production, composition, and application of coffee and its industrial residues, Food Bioprocess Technol 4, 661-672 (2011).

14. Kzitcina A., Koupletskaya N. B., Application of UV, IR, NMR and Mass Spectrometry in Organic Chemistry. Moscow University publishedment, 2 Edition (1979).

15. Osipov O. A., Minkin V. E., Handbook of Dipole moment. Vishayashcola, Moscow, P. 164 (1965).

(Received 10/4/2018; accepted $1 / 8 / 2018$ )

\title{
المتزازية النيكوتين على بقايا البن المضغوطة المكلسة والمحوّرة CACS ودراسة خواصها
}

\author{
يحيى وليد البزرة، رشا المصطفى، ملك الجبة \\ قسم الكيمياء ـ كلية العلوم - جامعة دمشق - سوريا.
}

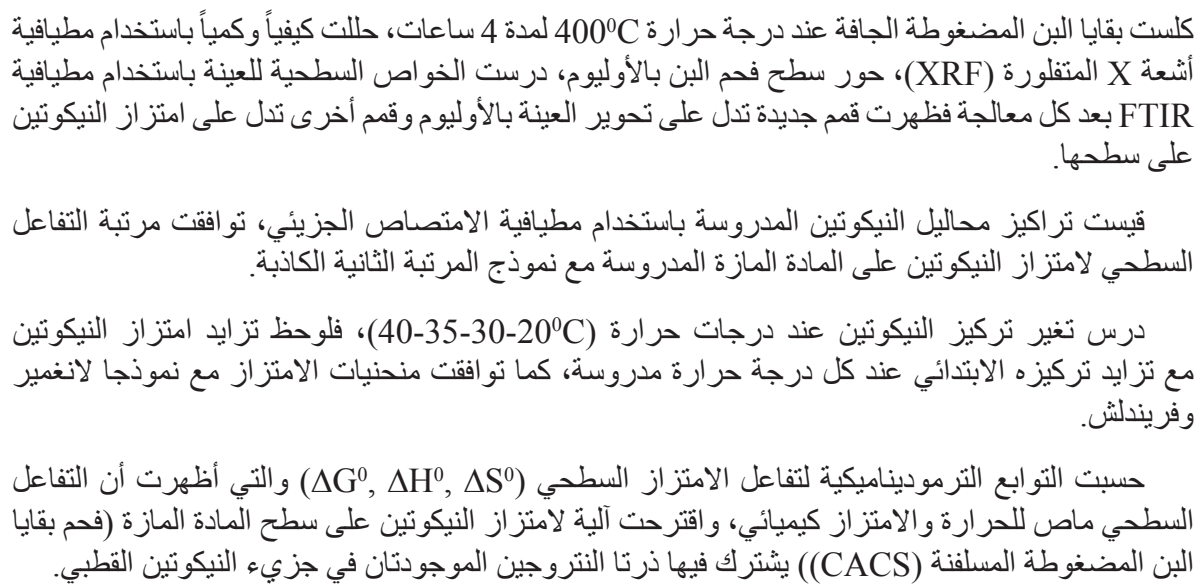

